\title{
IoT Door Lock Security System using Google Assistance
}

\author{
Priyanka G, Rachana J, Vijayalakshmi N, Abhisheka G S, Vinutha D C
}

\begin{abstract}
Nowadays security is the most common problem in door locking system. Anyone can break the door using hard objects and make a robbery of the home, offices and any other properties. This can lead to huge loss for the human economy. In this paper we are proposing a model, in which we used to lock and open the entryway utilizing the google help over the voice and stun IoT board and stun IoT application. The existing system rely on microcontroller, Global System for Mobile (GSM), GPS(Global Positioning System), various sensors, programming like MATLAB, biometric face affirmation, Iris scanner, RFID(Radio frequency identification ) technology [6], smart card and mystery express etc. In a colossal fragment of frameworks, Short Message Service (SMS) approach is utilized for correspondence so the structure, it requires some test to pass on message.
\end{abstract}

Keywords : Security, face confirmation, RFID, Smart Card and secret express.

\section{INTRODUCTION}

$\mathrm{T}_{\mathrm{h}}$ his Security watches out for insurance of our life and resources. Ensuring security of society and the essential things is huge for the slaughtering activity of unlawful managing. As needs be, dominatingly focusing on portal lock security or entryway security is fundamental to keep up a key conventional way from the further issues. Point of fact, even with the usage of mechanical locks, the awful direct, thefts get happened in view of how such stuns were possibly broken. Thusly, there is a need to structure other locks which can't be reasonably broken. Consequently, various makers present different sorts of cutting-edge passage locks, modified riddle enunciation-based segment locks, programming based entryway shocks, etc. which have been regularly utilized in house and the work environments.

The gadgets promotes that grant smart safety with cameras and digitized curls incorporating one or the other technology

Revised Manuscript Received on December 22, 2019.

Priyanka G, Dept. of ISE, Vidyavardhaka College of Engineering, Mysuru, Visvesvaraya Technological University, Belagavi, Karnataka. Email: priya.rtps@gmail.com

Rachana J, Dept. of ISE, Vidyavardhaka College of Engineering, Mysuru, Visvesvaraya Technological University, Belagavi, Karnataka. Email: rachanajk4@gmail.com

Vijayalakshmi N, Dept. of ISE, Vidyavardhaka College of Engineering,

Mysuru, Visvesvaraya Technological University, Belagavi, Karnataka. Email: vijayalakshmi33.n@gmail.com.

Abhisheka G S, Dept. of ISE, Vidyavardhaka College of Engineering,

Mysuru, Visvesvaraya Technological University, Belagavi, Karnataka. Email: abhisgowda849@gmail.com.

Vinutha D C, Dept. of ISE, Vidyavardhaka College of Engineering, Mysuru, Visvesvaraya Technological University, Belagavi, Karnataka.

Email: vinuthadc@vvce.ac.in to open the door. Distant interior security focuses on only if approach to the permanent as the proprietor is not physically present, by means of the model of internet and wireless networks [1].

The security right now become a significant issue out in the open or private organizations wherein different security frameworks suggested and proposed made few edgy strategies. Security structures a key for assurance of data, property, and altering development form burglary, terrible lead. From server branches to banks, security frameworks have changed into a need [5].

As IoT is picking up parcels and bunches of prominence, We can monitor any of these designed contraption in home and can work it remotely [3]. This is particularly worthwhile. Numerous organizations are endeavoring hard to create numerous productive home robotization gadgets. Hence, IoT has overwhelmed advertise. Likewise, there will be enormous development in the field of home robotization improvement is not very ousted future [3]. To render the design of smart home, we essentially base on two focus degrees of progress. One is IoT which associates with internetworking of the contraptions and fundamentally the likelihood of Artificial intelligence(AI) Where the computer itself can foresee the going with state as appeared by recorded data. We have shown a correspondence of an area with the seller[3]. Movement detecting, picture catching text warning is taken care of by camera. structure, Setting the request on the cell phone can regulate the lock [9],[10],[11],[2]. The information that is created is put away in distributed storage. Accordingly, all the preparing and control is done in cloud.[3]

IoT gadgets are typically microcontrollers which has restricted capacities. In light of that cutting-edge encryption calculations can't be executed in such gadgets. Just the most current form of microcontrollers has executed encryption calculations in equipment. That has negative ramifications in the event that a few deformities in calculations are discovered, at that point those gadgets can't be fixed with new forms[4].

\section{RELATED WORK}

At first entryway locking should be possible by utilizing keys. The electronic zone lock is misplaced, imitated and disabled as often as possible, which is referred to as the security device lower[5]. some utilization a secret key, savvy key entryway utilizing Radio frequency Signal a Regional Mobile Communication System Machine to Machine network, handwritten, face recognition, cellular communication network, fingerprint and RFID technology [5]. 
Following are the few weaknesses in the usage, for example, lock the console is excessively little, some older or people with portability issues, exceptionally awkward to utilize the console to enter username and secret phrase. The sensor on motion detection transforms the transition in the atmosphere into an effective voltage value in the form of incoming infrared rays [2]. Initially, keys can be used to lock the door. Thereafter to avoid the theft people found a digital locking system such as password based, Fingerprint [8] ,handwritten[6] In view of the previously mentioned weaknesses, this paper proposes a strategy for utilization of unique voice-controlled entryway lock.

\section{RESULTS AND DISCUSSIONS}

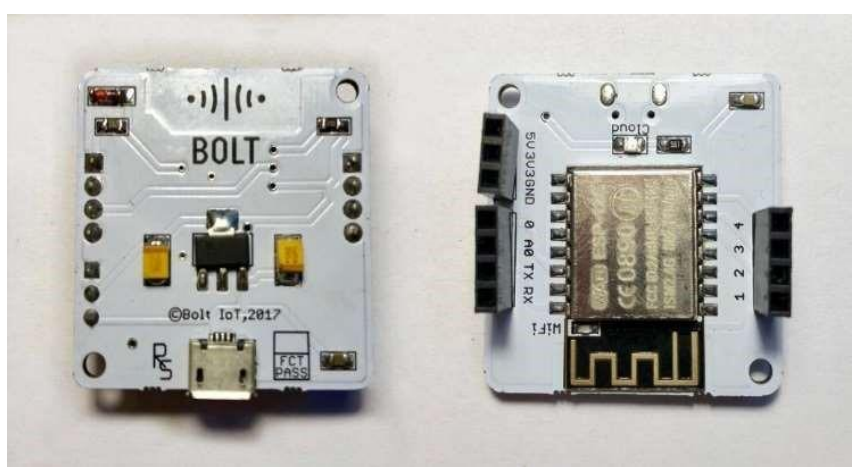

Figure 1: boalt iot board.[5]

BOLT is an Iot stage (Hardware + Cloud) that empowers client to manufacture IoT items and tasks. Utilizing BOLT, clients can control and screen gadgets from any piece of the world. It enables to embed Wireless Fidelity/ Global System for Mobile capacities inside various systems, or to fill in as an autonomous application [3]. The makers can present the Bolt gear in their thing, build up a custom UI and sometime later their clients can control their things utilizing the Bolt IoT application. BOLT oversees pay as you go premise, which means the makers have no capital speculations to get their things IoT empowered. This helps the low spending architect or customer to get preferred position of it. Aggregate of 12 Digital I/O pins are made open on BOLT v1. To be explicit pins $0,1,2,3,4,5,6$ and 7 closes by "a0, a1, a2 and a3". Figure 1 shows the boalt IOT board.

The Bolt improvement board is based out of the saw ESP8266 Wireless Fidelity module from ESP32-wroom-32d development board semiconductor as shown in figure 2 . Bolt IoT Platform assist us with building IoT ventures $80 \%$. Bolt has its very own cloud, no need of utilizing other cloud platform. The whole thing keeps running on cloud so it tends to be controlled from anyplace in the world. Bolt requests that we get to the I/O pins. Figure 1 shows the circuit diagram.

Digital R/W, Analog Read, Pulse-width modulation Write, etc., through an application program interface is prepared by bolt. The Bolt consists of $5 \mathrm{I} / \mathrm{O}$ pins and 1 analog stick which are right side of body connected with the cloud. So, on a very basic level to outline or investigate from these pins we have to make use of the application program interface calls.

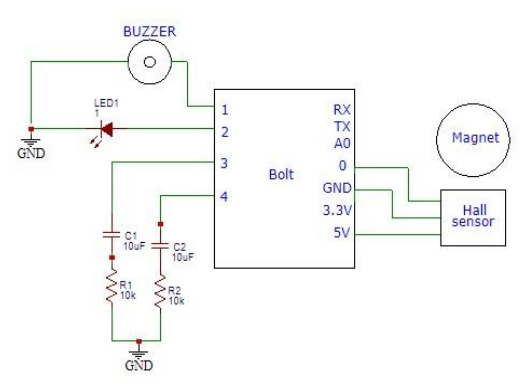

Figure 2: System Architecture

A.Hall effect sensors

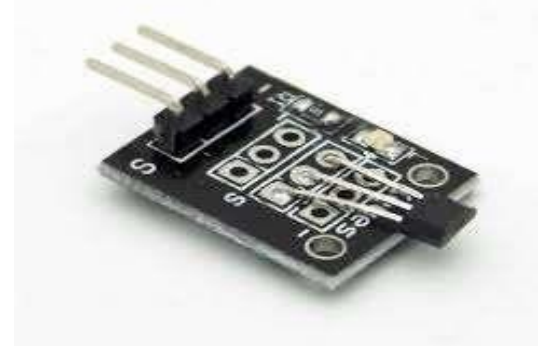

Figure 3: Hall effect sensor

Entry bring into being sensor is a piece of equipment that is second-hand to evaluate the moment fascinating field. They are old in brushless DC stimulating motors to find the place of the everlasting magnet. In the pictured controls with two similarly spaced magnets, the voltage from the sensor will tip double for every revolution. This pact is regularly old to normalize the promptness of CD-ROM drives.[3].

\section{B. Capacitor}

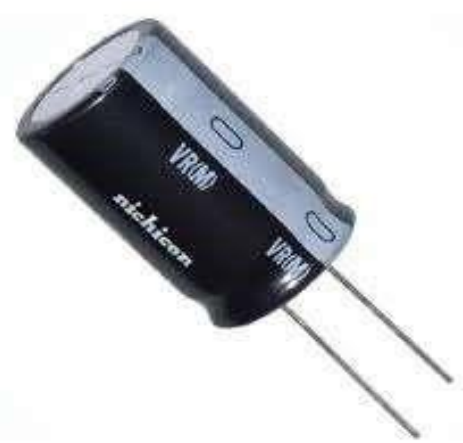

Figure 4: Capacitor

Capacitor is an electronic factor that plans invigorating charge. The capacitor is done of 2 meet conductors that are segregated by a dielectric material. The plates gather vitalizing charge what time coupled to weight source. Figure 4 shows the capacitor.

\section{LED}




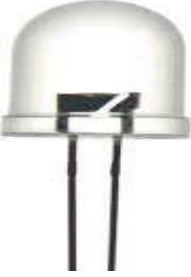

Figure 5: LED

Light-Emitting Diode is a semi-conductor rich foundation that transmits ignite what time stream courses through it. Electrons in the semiconductor again combines with electron openings, releasing imperativeness in the paper of photons. Figure 5 shows the LED. The impact of the sensible (showing up contrastingly in connection to the imperativeness of the photons) is calculated by the centrality major for electrons to cross the stretch baffle of the semi-conductor. dull happy is acquired by systems for complex semiconductors or a layer of light emitting phosphor on the semiconductor device.

\section{RESISTORS}

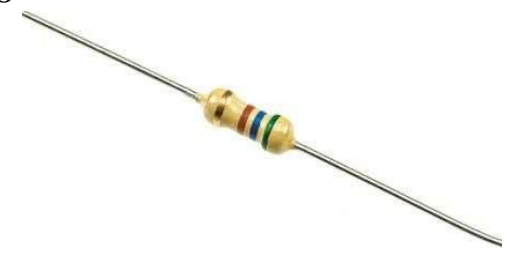

Figure 6: Resistors

Resistor is a separated two-terminal electrical segment that perceives electrical impediment as a circuit part. Figure 6 shows the resistors. In electronic circuits, resistors are used to lessen current stream, change sign levels, to keep voltages, affection remarkable parts, and end transmission lines, among various occupations.

\section{CONCLUSION}

In the present imaginatively propelled world, self-planning frameworks are extending savvy division so the headway in most recent advancement is dependably and promptly made on various most recent adjusted portal lock security structures. The necessity for a propelled passage lock security structure utilizing new advances produces a bit without a moment's delay as security become a goal or fundamental issue for everyone. In the perspective on the consistent inspiration to stress over this security whatever else, as adjusted security structures are here to direct it. This undertaking attempts to think all unfaltering entryway lock security frameworks in a far reaching way.

\section{REFERENCES}

1. Li Da Xu, Wu He, and Shancang Li. "Internet of Things in Industries: A Survey". IEEE transactions on industrial informatics, vol. 10, no. 4, November 2014

2. 1.J. Potts and S. Sukittanon, "Exploiting Bluetooth on Android mobile devices for home security application," 2012, pp. 1-4.

3. Faiz Aman, C Anitha. "Motion sensing and image capturing based smart door system on android platform", 2017 International Conference on Energy, Communication, Data Analytics and Soft Computing (ICECDS), 2017
4. Zvonimir Loncaric Marko Pavelic Marin Vukovic Mario Kušek "Internet of Things Cyber Security: Smart Door Lock System "978-1-5386-7189-4/18/\$31.00 @2018 IEEE

5. G. Sowjanya, S. Nagaraju. "Design and implementation of door access control and security system based on IOT", 2016 International Conference on Inventive Computation Technologies (ICICT), 2016

6. kuang-yow Lian, Sung-Jung Hsiao, ,WenTsai Sung, "Home Safety Handwriting Pattern Recognition System ", Proc. 11th IEEE Int. Conf. on Cognitive Informatics \& Cognitive Computing (ICCI*CC'12)

7. Suraj Pawar, Vipul Kithani, Sagar Ahuja, Sunita Sahu "Smart Home Security using IoT and Face Recognition" 2018 Fourth International Conference on Computing Communication Control and Automation (ICCUBEA)

8. Wu Ping, Wu Guichu, Xie Wenbin, Lu Jiangu, Li Peng, "Remote Monitoring Intelligent System Based on Fingerprint Door Lock”, 2010 International Conference on Intelligent Computation Technology and Automation.

9. Mrutyunjaya Sahani, and Biswajeet Pattnaik, "Web-Based Online Embedded Door Access Control and Home Security System Based on Face Recognition", 2015 International Conference on Circuit, Power and Computing Technologies [ICCPCT]

10. A. Kassem, S. E. Murr, G. Jamous, E. Saad, and M. Geagea, "A smart lock system using Wi-Fi security," 2016, pp. 222-225.

11. N. H. Ismail, Z. Tukiran, N. N. Shamsuddin, and E. I. . Saadon, "Android-based home door locks application via Bluetooth for disabled people," 2014, pp. 227-231.

\section{AUTHORS PROFILE}

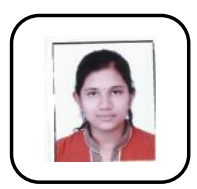

Priyanka G, Department of Information Science and Engineering, Vidyavardhaka College of Engineerin Student, Department of Information Science and Engineering,Karnataka, India

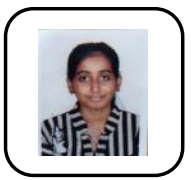

Rachana J, Department of Information Science and Engineering, Vidyavardhaka College of Engineerin Student, Department of Information Science and Engineering,Karnataka, India

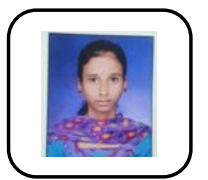

Vijayalakshmi N, Department of Information Science and Engineering, Vidyavardhaka College of Engineerin Student, Department of Information Science and Engineering,Karnataka, India

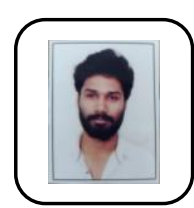

Abhisheka G S, Department of Information Science and Engineering, Vidyavardhaka College of Engineerin Student, Department of Information Science and Engineering,Karnataka, India

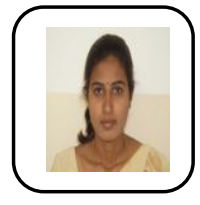

Mrs. Vinutha D C, working as Associate Professor, ISE Dept., VVCE, Mysuru. Her research interests include Big Data Systems, Hadoop, Parallel Processing mechanisms, Scheduling. She has published more than 14 research papers. 